\section{Anemia aplásica asociada a infección por el virus de la hepatitis $\mathrm{C}$}

\section{Sr. Director:}

La anemia aplásica (AA) es una enfermedad de baja incidencia y elevada mortalidad, cuya causa es desconocida (1). Se han documentado más de 200 casos de AA asociada a hepatitis (AAAH) (2), la mayoría no parecen estar causados por los virus de hepatitis conocidos, aunque algunos casos se han asociado al virus de la hepatitis C (VHC), en España se han comunicado dos casos $(3,4)$. El posible efecto de los diferentes tratamientos en la función hepática y la carga viral no se ha estudiado en detalle. Ocasionalmente se ha comunicado la eliminación del virus y la mejoría del estado clínico con el uso de interferón en citopenias aisladas de origen autoinmunes (5). Presentamos un caso de AAAH en un paciente con infección por VHC, que no respondió al tratamiento antiviral con peginterferon alfa y ribavirina.

Varón de 80 años con antecedentes de toracoplastia derecha, resección prostática, y arritmia cardiaca. Toma habitual de amiodarona, acido acetil salicílico, y lansoprazol. Un mes y medio antes de su ingreso desarrolla astenia, pérdida de peso, molestias post-prandiales en región epigástrica y prurito generalizado. Las constantes eran normales y en la exploración destacaba aspecto caquéctico, palidez cutánea e ictericia cutáneo-mucosa, no se palpaban adenopatías, el tacto rectal fue normal. Analítica: leucocitos $0,9 \times 10^{9} / 1$, hemoglobina $5,4 \mathrm{~g} / \mathrm{dl}$, hematocrito $15,5 \%$, plaquetas $6 \times 10^{9} / 1$, tiempo de protrombina 63\%, AST $178 \mathrm{UI} / 1$, ALT $165 \mathrm{UI} / \mathrm{l}, \mathrm{GGT} 177 \mathrm{UI} / 1, \mathrm{~F}$. alcalina $328 \mathrm{U} / 1$, bilirrubina total 4,3 $\mathrm{mg} / \mathrm{dl}$, proteínas totales $5,1 \mathrm{~g} / \mathrm{dl}$, albúmina 1,8 g/dl, ferritina 3631 $\mathrm{ng} / \mathrm{ml}$, folato $3 \mathrm{ng} / \mathrm{ml}$, el proteinograma con hipoalbuminemia, vitamina B12, y hormonas tiroideas normales. Anticuerpos antinucleares, anti-DNA, anticitoplasma de neutrofilo y crioglobulinas negativos. Los marcadores tumorales realizados $(\alpha$-fetoproteina, CEA, CA19.9, SCC, PSA, enolasa neuronal específica) fueron negativos. La serología de virus de hepatitis AIg $G$ fue positiva, las de hepatitis B, Epstein Barr y parvovirus B19 fueron negativas, y la de citomegalovirus positiva (IgG e IgM), el cultivo y antigeno de citomegalovirus fueron negativos. La serología del VHC fue positiva, y la carga viral del VHC fue superior a 69.000.000 UI/ml (7,84 log) Cobas TaqMan $\mathrm{HCV}^{\circledR}$ (Roche), el genotipo fue 1b. El aspirado medular fue hipocelular sin infiltración neoplásica, y la biopsia ósea fue concordante con aplasia de medula ósea (MO). La tomografía computarizada abdominal mostró la presencia de líquido ascitico y datos compatibles con infiltración grasa hepática y un probable hemangioma en el lóbulo izquierdo. Se realizo soporte hematológico con transfusiones de concentrados de hematíes y plaquetas, y tratamiento con filgrastim. Se decidió debido al estado clínico del paciente no administrar tratamiento inmunosupresor, e iniciar tratamiento con peginterferon alfa y ribavirina, que se administro durante dos semanas, descendiendo la AST a 66 UI/1, ALT 27 UI/1, y la carga viral a $553.000 \mathrm{UI} / \mathrm{ml}(5,74 \mathrm{log})$, persistió la elevación de bilirrubina, el deterioro de la coagulación y la pancitopenia. El paciente falleció a los 21 días de ingreso con un cuadro febril y antigenemia de Aspergillus positivo.

El VHC se ha relacionado ocasionalmente con el desarrollo de enfermedades sistémicas autoinmunes, como el síndrome de Sjögren, artritis reumatoide, y el lupus eritematoso sistémico, su aparición asociada a la enfermedad hepática crónica empeora el pronostico de estos pacientes (3). La presencia de citopenias graves asociadas al VHC, es infrecuente, y suele relacionarse con la utilización de interferón o con el hiperesplenismo que presentan algunos de estos pacientes (6). La depresión de la función de la MO asociada a la hepatitis se describió en 1955, la incidencia de AAAH se estima entre el 0,1 y el 0,2\% (7). Diversos estudios han abordado el papel del VHC en la patogénesis de la AA, algunos lo detectan entre el 10 y $36 \%$ de los pacientes con AAAH $(8,9)$. Otros describen una ausencia de infección por el VHC o una prevalencia similar a la de la población control (10).

Este síndrome, probablemente, esta mediado por un mecanismo inmunopatológico, a través de linfocitos T que suprimen la MO y la infiltración hepática con células CD8 activadas $(2,10)$. Los corticoides se consideran el tratamiento de elección, y los inmunosupresores se deben utilizar en los casos refractarios (3). El transplante de $\mathrm{MO}$ en estos pacientes tiene una supervivencia similar a la de los controles con AA no asociada a hepatitis (2). Debido al carácter inmune de este trastorno, no se ha analizado el papel de la terapia antiviral, el periodo de tratamiento de dos semanas en nuestro paciente no permite extraer conclusiones, si bien se debe destacar que la caída de la carga viral (superior a 2 logaritmos) no tuvo ningún efecto beneficioso sobre la AA.

En los casos de AA se debe de tener en cuenta en el diagnostico etiológico, la posibilidad de la infección con el VHC. 


\section{E. Morano Amado, A. Baz Lomba, I. Solla Ruiz ${ }^{1}$, J. M. Lite Álvarez}

Servicios de Medicina Interna-Infecciosas y ${ }^{1}$ Hematología. Universidad de Vigo. Hospital Meixoeiro. Vigo

1. Incidence of aplastic anemia: The relevance of diagnostic criteria. By the International Agranulocytosis and Aplastic Anemia Study. Blood 1987; 70: 1718-21.

2. Safadi R, Or R, Ilan Y, Naparstek E, Nagler A, Klein A, et al. Lack of known hepatitis virus in hepatitis-associated aplastic anemia and outcome after bone marrow transplantation. Bone Marrow Transplant 2001; 27: $183-90$.

3. Ramos-Casals M, García-Carrasco M, López-Medrano F, Trejo O, Forns X, Lopez-Guillermo A, et al. Severe autoimmune cytopenias in treatment-naive hepatitis $\mathrm{C}$ virus infection: Clinical description of 35 cases. Medicine 2003; 82: 87-96.
4. Gomez de la Torre R, Florido Mancheno JI, Claros Gonzalez IJ, Rubio Barbon S. Chronic hepatitis C with bone marrow aplasia. Med Clin (Barc) 1994; 102: 715-6.

5. Levi S, Foster C, Hodgson HJ, Ward KN, So A, Garson JA, et al. Chronic liver disease due to hepatitis C. BMJ 1993; 306: 1054-6.

6. Hernandez F, Blanquer A, Linares M, Lopez A, Tarin F, Cervero A. Autoimmune thrombocytopenia associated with hepatitis $\mathrm{C}$ virus infection. Acta Haematol 1998; 99: 217-20.

7. Dhingra K, Michels SD, Winton EF, Gordon DS. Transient bone marrow aplasia associated with non-A, non-B hepatitis. Am J Hematol 1988; 29: 168-71.

8. Pol S, Driss F, Devergie A, Brechot C, Berthelot P, Gluckman E. Is hepatitis $\mathrm{C}$ virus involved in hepatitis-associated aplastic anemia? Annals Intern Med 1990; 113: 435-7.

9. Hibbs JR, Frickhofen N, Rosenfeld SJ, Feinstone SM, Kojima S, Bacigalupo A, et al. Aplastic anemia and viral hepatitis. Non-A, Non-B, Non-C? JAMA 1992; 267: 2051-4

10. Brown K, Tisdale J, Barrett A, Dunbar C, Young N. Hepatitis-associated aplastic anemia. N Engl J Med 1997; 336: 1059-64. 